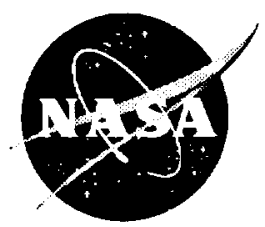

\title{
The Effects of Blade Count on Boundary Layer Development in a Low-Pressure Turbine
}

Daniel J. Dorney and Horia C. Flitan

Virginia Commonwealth University, Richmond, Virginia

David E. Ashpis

Glenn Research Center, Cleveland, Ohio

William J. Solomon

Ohio Aerospace Institute, Cleveland, Ohio

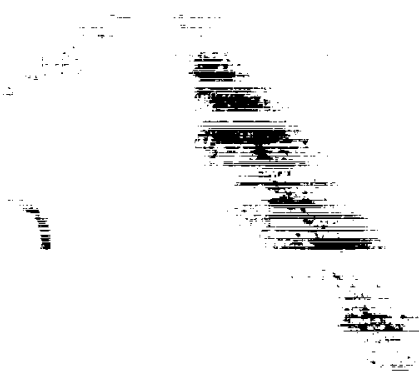


Since its founding, NASA has been dedicated to the advancement of aeronautics and space science. The NASA Scientific and Technical Information (STI) Program Office plays a key part in helping NASA maintain this important role.

The NASA STI Program Office is operated by Langley Research Center, the Lead Center for NASA's scientific and technical information. The NASA STI Program Office provides access to the NASA STI Database, the largest collection of aeronautical and space science STI in the world. The Program Office is also NASA's institutional mechanism for disseminating the results of its research and development activities. These results are published by NASA in the NASA STI Report Series, which includes the following report types:

- TECHNICAL PUBLICATION. Reports of completed research or a major significant phase of research that present the results of NASA programs and include extensive data or theoretical analysis. Includes compilations of significant scientific and technical data and information deemed to be of continuing reference value. NASA's counterpart of peerreviewed formal professional papers but has less stringent limitations on manuscript length and extent of graphic presentations.

- TECHNICAL MEMORANDUM. Scientific and technical findings that are preliminary or of specialized interest, e.g., quick release reports, working papers, and bibliographies that contain minimal annotation. Does not contain extensive analysis.

- CONTRACTOR REPORT. Scientific and technical findings by NASA-sponsored contractors and grantees.
- CONFERENCE PUBLICATION. Collected papers from scientific and technical conferences, symposia, seminars, or other meetings sponsored or cosponsored by NASA.

- SPECIAL PUBLICATION. Scientific, technical, or historical information from NASA programs, projects, and missions, often concerned with subjects having substantial public interest.

- TECHNTCAL TRANSLATION. Englishlanguage translations of foreign scientific and technical material pertinent to NASA's mission.

Specialized services that complement the STI Program Office's diverse offerings include creating custom thesauri, building customized data bases, organizing and publishing research results ... even providing videos.

For more information about the NASA STI Program Office, see the following:

- Access the NASA STI Program Home Page at http://www.sti.nasa.gov

- E-mail your question via the Internet to help@sti.nasa.gov

- Fax your question to the NASA Access Help Desk at (301) 621-0134

- Telephone the NASA Access Help Desk at (301) 621-0390

- Write to:

NASA Access Help Desk

NASA Center for AeroSpace Information 7121 Standard Drive Hanover, MD 21076 
NASA/TM-2000-209911

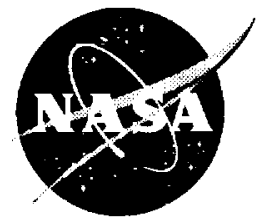

\section{The Effects of Blade Count on Boundary Layer Development in a Low-Pressure Turbine}

Daniel J. Dorney and Horia C. Flitan

Virginia Commonwealth University, Richmond, Virginia

David E. Ashpis

Glenn Research Center, Cleveland, Ohio

William J. Solomon

Ohio Aerospace Institute, Cleveland, Ohio

Prepared for the

38th Aerospace Sciences Meeting and Exhibit

sponsored by the American Institute of Aeronautics and Astronautics

Reno, Nevada, January 10-13, 2000

National Aeronautics and

Space Administration

Glenn Research Center 


\section{Acknowledgments}

The work of the first author was supported by NASA Glenn Research Center under Grant NCC3-645.

Trade names or manufacturers' names are used in this report for identification only. This usage does not constitute an official endorsement, either expressed or implied, by the National Aeronautics and Space Administration.

NASA Center for Aerospace Information 7121 Standard Drive Hanover, MD 21076

Price Code: A03
National Technical Information Service 5285 Port Royal Road Springfield, VA 22100 Price Code: A03 


\section{THE EFFECTS OF BLADE COUNT ON BOUNDARY LAYER DEVELOPMENT IN A LOW-PRESSURE TURBINE}

\author{
Daniel J. Dorney * \\ Virginia Commonwealth University \\ Richmond, VA \\ David E. Ashpis ${ }^{b}$ \\ NASA Glenn Research Center \\ Cleveland, $\mathrm{OH}$
}

\author{
Horia C. Flitan ${ }^{a}$ \\ Virginia Commonwealth University \\ Richmond, VA \\ IVilliam J. Solomon: \\ Ohio Aerospace Institute \\ C'lereland. OH
}

\begin{abstract}
Experimental data from jet-engine tests have indicated that turbine efficiencies at takeoff can be as much as two points higher than those at cruise conditions. Recent studies have shown that Reynolds number effects contribute to the lower efficiencies at cruise conditions. In the current study numerical simulations have been performed to study the boundary layer development in a two-stage low-pressure turbine, and to evaluate the models available for low Reynolds number flows in turbomachinery. In a previous study using the same geometry the predicted time-averaged boundary layer quantities showed excellent agreement with the experimental data, but the predicted unsteady results showed only fair agreement with the experimental data. It was surmised that the blade count approximation used in the numerical simulations generated more unsteadiness than was observed in the experiments. In this study a more accurate blade approximation has been used to model the turbine, and the method of post-processing the boundary layer information has been modified to more closely resemble the process used in the experiments. The predicted results show improved agreement with the unsteady experimental data.
\end{abstract}

\section{NOMENCLATURE}

$C_{f} \quad$ Skin friction coefficient

$H$ Shape factor

*Associate Professor, Senior Member AIAA.

a Ph.D. Candidate.

b Aerospace Engineer, Senior Member AIAA.

c Senior Research Associate, Member AIAA.
$M \quad$ Mach number

$N \quad$ Nozzle/vane

$P \quad$ Pressure

$P_{t} \quad$ Total Pressure

Re Reynolds number (axial chord, inlet vel.)

$S \quad$ Entropy, arc length

SSL Normalized suction surface arc length

$\mathrm{Tu}$ Turbulence level

$u$ Local velocity

$U_{\infty} \quad$ Free stream velocity

$\delta^{*} \quad$ Displacement thickness/suction surface length

$\eta \quad$ Efficiency

$\lambda$ Pressure gradient parameter

$\nu \quad$ Kinematic viscosity

$\rho \quad$ Density

$\sigma \quad$ Intermittency function

$\theta \quad$ Momentum thickness

$\Omega \quad$ Rotational velocity

\section{SUBSCRIPTS}

tt Total-to-total quantity

wet Wetted distance

$\theta \quad$ Momentum thickness

1 First nozzle inlet

2 First nozzle exit/first rotor inlet

$3 \quad$ First rotor exit/second nozzle inlet

4 Second nozzle exit/second rotor inlet

5 Second rotor exit

\section{INTRODUCTION}

Experimental data from jet-engine tests have indicated that unsteady blade row (wake) interactions 
and separation can have a significant impact on the efficiency of turbine stages. The effects of these interactions can be intensified in low-pressure turbine (LPT) stages because of the low Reynolds number operating environment. Measured turbine efficiencies at takeoff can be as much as two points higher than those at cruise conditions [1]. Thus, during the last decade a significant amount of effort has been put into determining the effects of transition and turbulence on the performance of low pressure turbine stages. Experimental investigations have been performed, for example, by Hodson $t$ al $[2,3,4,5]$, Halstead et al. [6, 7], Qiu et al. [8], Sohn et al. [9] and Boyle et al. [10]. These investigations have helped identify/clarify the roles that factors such as the Reynolds number, free stream turbulence intensity, pressure gradient and curvature have in the generation of losses. In particular, it has been determined that [1]:

- At low to moderate Reynolds numbers there is a laminar region extending some distance from the leading edge.

- The boundary layer may separate, particularly on the suction surface of the blade. Separation may occur in the form of a closed bubble, or as massive separation with no reattachment (resulting in large losses). The pressure surface may have cove separation, and small separation bubbles may exist near the leading edge. The separation bubbles often originate in transitional flow, while reattachment is usually in turbulent flow.

- The interaction of incoming wakes with the boundary layer often creates a convected transitional or turbulent patch, which is trailed by a "calmed" region. The calmed region is a relaxation region between the patch and the laminar boundary layer.

In parallel to the experimental investigations, there have been significant analytical efforts to improve the modeling of transition. Examples of such efforts include the works of Mayle [11], Reshotko [12] and Gostelow et al. [13, 14]. These newer models show promise of providing accurate transition predictions over a wide range of flow conditions [15], although they have yet to be implemented into the numerical flow analyses used by the turbine design community. Some recent computational investigations of interest include the works of Chernobrovkin and Lakshminarayana [16], Kang and Lakshminarayana [17], Huang and Xiong [18] and Eulitz and Engel [19].

The focus of the current effort has been to use a viscous, unsteady quasi-three-dimensional Navier-
Stokes analysis to study boundary layer development in a two-stage low-pressure turbine. A two-layer algebraic turbulence model, along with natural and bubble transition models, have been evaluated at both take-off and cruise operating conditions. The geometry used in the simulations has been the subject of extensive experiments $[6,7]$. A recent investigation by Dorney $\epsilon t$ al. compared the results of quasi-three-dimensional simulations with experimental data for the same geometry [20]. The predicted time-averaged boundary layer quantities showed excellent agreement with the experimental data, but the predicted unsteady results showed only fair agreement with the experimental data. It was hypothesized that unsteady effects associated with modified blade counts in the numerical simulations generated more unsteadiness than was observed in the experiments. The goal of the current work has been to quantify these effects of using more accurate blade counts, and to study the effects of post-processing techniques on the predicted results.

\section{ALGORITHM}

In the computational procedure the flow field is divided into two types of zones. O-type grids are used to resolve the flow field near the airfoils. The O-grids are overlaid on $\mathrm{H}$-grids which are used to resolve the remainder of the flow field. The $\mathrm{H}$-grids are allowed to slip relative to one another to simulate the relative motion between rotors and stators. The thin-layer or full Navier-Stokes equations are solved on both the $\mathrm{O}$ - and $\mathrm{H}$-grids. The governing equations are cast in the strong conservation form. A fully implicit, finitedifference method is used to advance the solution of the governing equations in time. A Newton-Raphson subiteration scheme is used to reduce the linearization and factorization errors at each time step. The convective terms are evaluated using a third-orderaccurate upwind-biased Roe scheme. The viscous terms are evaluated using second-order accurate central differences and the scheme is second-order accurate in time. Message Passing Interface (MPI) software has been implemented into the numerical analysis to reduce the computation time for large-scale simulations. Details of the solution procedure and boundary conditions are discussed in Ref. [21]

\section{TURBULENCE MODEL}

The two-layer algebraic model based on the work of Baldwin and Lomax (BL) was used to model turbulence [22]. Several modifications were made to the original BL model based on previous experiences with compressor and turbine geometries: 
- The switchover location between the inner and outer models cannot move more than a specified number of grid points between adjacent streamwise locations. This eliminates non-physical gradients in the turbulent viscosity near separation points.

- A second derivative smoothing function is used on the turbulent viscosity field in separated flow regions. This also helps remove non-physical gradients in the turbulent viscosity in separation regions.

- A cutoff value is imposed on the turbulent viscosity (nominally 1200 times the free stream laminar viscosity).

The comparison of predicted and experimental integral boundary layer quantities warrants discussion of the technique used to determine the location of the boundary layer edge in the simulations. The following steps, based on the work of Davis et al. [23], were used to determine the edge of the boundary layer:

1. determine the minimum value of $\left|U_{\infty}-u\right|$, where $U_{\infty}$ is based on isentropic conditions

2 . correct the location based on where the local vorticity exceeds a specified limiting value

3 . within the new range, determine where $u$ is greater than $U_{\infty}$

The results presented in Ref. [20] for the current geometry exhibited larger variations in the unsteady displacement and momentum thickness distributions than were observed in the experiments. One possible cause of the discrepancies was that the experimental data acquisition system could measure boundary layer thicknesses to a maximum height of approximately $1.2 \mathrm{~mm}$, while there were no limitations placed on the boundary layer height in the simulations. Therefore, as part of post-processing in the current study the predicted boundary layer thicknesses were clipped at a maximum height of $1.2 \mathrm{~mm}$.

\section{TRANSITION MODELS}

The low Reynolds number environment in lowpressure turbines suggests that the flow may be transitional. The natural transition model utilized in this study was developed by Abu-Ghannam and Shaw (ABS) [24].

\section{ABS Model}

The ABS model determines the start of transition based on the momentum thickness Reynolds number

$$
R \epsilon_{\theta}=163+\exp \left[F\left(\lambda_{\theta}\right)-\frac{F\left(\lambda_{\theta}\right)}{6.91} T u\right]
$$

where

$$
\begin{aligned}
F\left(\lambda_{\theta}\right) & \left.=6.91+12.75 \lambda_{\theta}+63.64\left(\lambda_{\theta}\right)^{2} \lambda_{\theta}<02\right) \\
F\left(\lambda_{\theta}\right) & =6.91+2.48 \lambda_{\theta}-12.27\left(\lambda_{\theta}\right)^{2} \quad \lambda_{\theta}>0(3) \\
\lambda_{\theta} & =\frac{\theta^{2}}{\nu} \frac{d U_{\infty}}{d S}
\end{aligned}
$$

This model is considered valid up to turbulence levels of $T u=10 \%$. The end of the transition region is calculated as

$$
R \epsilon_{L}=31.8\left(R e_{\theta}\right)^{1.6}
$$

In the region between the start and end of transition the intermittency function, $\sigma$, is determined using the model developed by Dhawan and Narasimha [25],

$$
\sigma=1-\exp \left(-4.64 \xi^{2}\right)
$$

Note, the intermittency function, which has a value of $\sigma=0$ for laminar flow and $\sigma=1$ for turbulent flow, is multiplied by value of the viscosity calculated in the turbulence model. The current implementation of the ABS model has been tested on both compressor and turbine geometries $[26,27]$.

\section{Roberts" Model}

For cases involving separation bubbles the model developed by Roberts [28], and modified by Davis et al. [29], is used:

$$
R e_{\theta}=25000 \log _{10}(1 / \tanh (0.173205 T u))
$$

Instantaneous transition is assumed using the bubble model.

\section{GEOMETRY AND GRID}

The test article used in this study has been studied extensively by Halstead $\mathrm{et}$ al. $[6,7]$. The turbine is typical of those found in modern aircraft engines (see Fig. 1). The turbine design parameters are shown in Table 1 .

The experimental turbine contains 82 first-stage vanes, 72 first-stage rotors, 108 second-stage vanes and 72 second-stage rotors (i.e., a 82-72-108-72 blade count). In the previous study a blade count of $78-78$ 104-78 was assumed, thus requiring the use of 3 firststage vanes, 3 first-stage rotors, 4 second-stage vanes 


\begin{tabular}{|l|c|c|c|}
\hline Quantity & N1 & N2 & Rotor \\
\hline Solidity & 1.64 & 1.68 & 1.48 \\
Aspect Ratio & 3.97 & 5.10 & 3.87 \\
Chord, mm & 76.2 & 59.7 & 78.7 \\
Stagger, deg from axial & 39.8 & 22.9 & 34.9 \\
Camber, deg & 60.0 & 102.4 & 96.9 \\
No. of airfoils & 82 & 108 & 72 \\
Axial gap, mm & 25.4 & 25.4 & - \\
\hline
\end{tabular}

Table 1: Turbine design parameters.

and 3 second-stage rotors in the simulations [20]. In the current study a $81-72-108-72$ blade count approximation has been used, requiring the use of 9 first-stage vanes, 8 first-stage rotors, 12 second-stage vanes and 8 second-stage rotors in the simulations. For completeness, however, a set of 3-3-4-3 simulations were computed using the boundary layer clipping technique described earlier.

In keeping with the previous simulations, the O-grids for each blade passage contain $251 \times 51$ (streamwise $\times$ tangential) grid points. The $\mathrm{H}$-grids in the first-stage nozzle passage each contain $108 \times 96$ grid points, the $\mathrm{H}$-grids in the first-stage rotor passage each contain $125 \times 96$ grid points, the $\mathrm{H}$-grids in the second-stage nozzle passage each contain $120 \times 96$ grid points and the $\mathrm{H}$-grids in the second-stage rotor passage each contain $175 \times 96$ grid points. Thus, the complete grid topology contains 935,589 grid points (see Fig. 2, where every fifth grid point is shown for clarity).

The average value of $y^{+}$, the non-dimensional distance of the first grid point above the surface, was approximately 1.0 for all four blade rows. The dimensions of the O-grid were arrived at based on the value of $y^{+}$and the number of points within the boundary layer, while the dimensions of the H-grid were determined by performing wake convection simulations in the absence of airfoils.

The simulations were run on four processors of a Silicon Graphics Inc. (SGI) Origin200 workstation with $195-\mathrm{MHz}$ processors. The average computation time was 10.0 secs/iteration. Each simulation was run for 10 global periods, at 50,000 time steps per global period. A global period is defined as the second-stage rotor moving through a distance equal to 12 second-stage nozzle pitches or, similarly, the first-stage rotor moving through a distance equal to 9 first-stage nozzle pitches. The 10 global periods enabled the efficiency, losses and integral boundary layer quantities to become time periodic.

\section{RESULTS}

Two different operating points have been studied: one at takeoff conditions (Point 5A) and one at cruise conditions (Point 5D). The parameters associated with the two test conditions are outlined in Table 2. In accordance with the experiments, the free stream turbulence level (used in the transition model) was set at $T u=3 \%$.

\begin{tabular}{|l|c|c|}
\hline & \multicolumn{2}{|c|}{ Test Point } \\
\hline Quantity & $5 \mathrm{~A}$ & $5 \mathrm{D}$ \\
\hline$R_{\epsilon}$ & 101,200 & 34,300 \\
$T_{t 1}\left({ }^{\circ} \mathrm{N}\right)$ & 287.8 & 287.8 \\
$P_{t 1}\left(\mathrm{~N} / \mathrm{m}^{2}\right)$ & 97,642 & 100,839 \\
$P_{1}\left(\mathrm{~N} / \mathrm{m}^{2}\right)$ & 96,514 & 100,716 \\
$\alpha_{1}, \mathrm{deg}$ from axial & 0.0 & 0.0 \\
$\Omega(R P M)$ & 599.7 & 185.1 \\
$M_{1}$ & 0.1289 & 0.0417 \\
$P_{5} / P_{t 1}$ & 0.8614 & 0.8614 \\
\hline
\end{tabular}

Table 2: Turbine design parameters.

\section{Point 5A}

Entropy contours are useful for tracking the convection of airfoil wakes. Figure 3 shows instantaneous non-dimensional entropy contours for the 9 $8-12-8$ blade count. The stretching of the wakes between the suction and pressure surfaces of adjacent airfoils is evident. In addition, it is possible to track the wakes from the first-stage nozzle downstream into the second-stage rotor passage. Instantaneous $\mathrm{Mach}$ contours are shown in Fig. 4. The passage-to-passage variations present in both Figs. 3 and 4 underscore the importance of using an accurate blade count approximation.

The predicted and experimental normalized blade loadings for the second nozzle and second rotor are shown in Figs. 5 and 6, respectively. The loading distributions were similar in both the 9-8-12-8 and 3-3-4-3 simulations, therefore only the results from the 9-8-12-8 simulation are shown. The predicted results exhibit good agreement with the experimental data, except in the suction surface leading edge region of the second nozzle. The differences in this region suggest the flow entering the second nozzle in the simulations has somewhat greater positive incidence. On the second rotor, both the numerical results and experimental data show an acceleration region near the suction surface leading edge followed by a zone of constant velocity, a second acceleration region and 
finally a deceleration zone as the flow moves downstream of the throat into the uncovered portion of the passage.

Figure 7 contains the experimental and predicted (with clipped boundary layers) displacement thickness histories at $50 \%$ of the wetted distance on the suction surface of the second-stage nozzle over 4 rotor wake-passing periods. For comparison purposes, Fig. 8 displays the effects of the boundary layer clipping on the predicted 3-3-4-3 results. The different blade count approximations have little effect on the predicted results, with both simulations showing the experimentally-observed increase in displacement thickness with the passing of the rotor wakes. The effects of clipping the boundary layer are more pronounced than the effects of blade count approximation at this location (see Fig. 8). The clipping eliminates the peaks observed in the results presented in Ref. [20], while preserving the character of the boundary layer in between wake passings.

The experimental and predicted displacement thickness histories at $68 \%$ of the suction surface wetted distance are shown in Fig. 9, while the corresponding comparison of the clipped and unclipped solutions are shown in Fig. 10. At this location, the distribution from the 9-8-12-8 simulation shows more unsteadiness than was predicted in the 3-3-4-3 simulation, most notably just before the passing of the rotor wake. Both simulations indicate more rapid decay of the displacement thickness after the passing of the rotor wake than was observed in the experiments. Similar to the results at $50 \%$, the effects of clipping are greater than the effects of the blade count approximation (see Fig. 10). Note, while the unsteady results in Fig. 9 exhibit only fair agreement with the experimental data, the match is significantly closer than in the previous simulations without boundary layer clipping [20].

At $82 \%$ of the wetted distance on the suction surface the predicted displacement thickness history from the 9-8-12-8 simulation shows much closer agreement with the experimental data than the results of the 3-3-4-3 simulation (see Fig. 11). In particular, the 9-8-12-8 simulation begins to mimic the gradual decrease in the displacement thickness after the passing of the rotor wake. The effects of boundary layer clipping become more important approaching the trailing edge region (see Fig. 12). Similar to the results in Figs. 8 and 10 the clipping has only minimal effects on the histories in between the passings of the rotor wakes.

Figure 13 illustrates the predicted and experimental displacement thickness histories at $94 \%$ of the wetted distance on the suction surface. The results of both simulations exhibit only fair agreement with the experimental data, although the results of the 9-812-8 simulation lie slightly closer to the data. The discrepancies beteen the predicted results and the experimental data, however, are much smaller than those without boundary layer clipping (see Fig. 14 and Ref. [20]). The effects of the clipping appear to be two-fold. First the clipping makes the postprocessing in the analysis more representative of the data acquisition in the experiments. Second, the clipping appears to account for the relaxation of the boundary layer, which is not included in the BaldwinLomax turbulence model.

Comparisons of the experimental and predicted time-averaged suction surface displacement thickness distributions are shown in Fig. 15. Also included in Fig. 15 are the maximum and minimum displacement thickness distributions predicted in the simulations. The results of both simulations show close agreement with the experimental data. The 9-8-12-8 solution displays more unsteadiness, as indicated by the area between the minimum and maximum thickness distributions.

\section{Point 5D}

The entropy and Mach contours at cruise conditions are similar to those shown in Ref. [20], and therefore are omitted here.

The predicted and experimental displacement thickness histories at $50 \%$ of the wetted distance along the suction surface of the second-stage nozzle are show in Fig. 16. Similar to the results at the takeoff conditions, the effects of blade count approximation are small at this location. The effects of the boundary layer clipping are also relatively small (see Fig. 17), although it must be noted that the unclipped distributions (in general) did not display the rapid, large amplitude variations observed at the cruise operating conditions [20]. The predicted results show only fair agreement with the data, as the decrease in the displacement thickness after the passing of the rotor wake is overestimated.

Figure 18 contains the predicted and experimental displacement thicknesses at $68 \%$ of the suction surface wetted distance. The results of the 9-8-128 simulation display better phase agreement with the data than the results of the 3-3-4-3 simulation. The results of both simulations show the doublepeak nature of the distribution observed in the experiments. The effects of the boundary layer clipping at the $68 \%$ location, which are shown in Fig. 19, are greater than at the $50 \%$ location. The increasingly large effects of the clipping with wetted distance is not surprising because the unsteadiness in 
the boundary layer increases downstream of the transition/separation points.

At $82 \%$ of the wetted distance on the suction surface the predicted displacement thickness histories show fair agreement with the experimental data (see Fig. 20), although the results of the 3-3-4-3 simulation more closely resemble the shape of the experimental distribution. The clipping has a significant effect at the $82 \%$ location where the solution displays two distinct peaks and valleys per blade passing (similar to the experimental data), while the unclipped solution shows only one (see Fig. 21).

Figure 22 illustrates the predicted and experimental displacement thickness histories at $94 \%$ of the wetted distance on the suction surface. Although both simulations show good agreement with the experimental data, the shape of the distribution from 98-12-8 simulation more closely resembles that of the data. The effects of the boundary layer clipping are minimal at this location (see Fig. 23).

Comparisons of the experimental and predicted time-averaged suction surface displacement thickness distributions are shown in Fig. 24. The results of both the 3-3-4-3 and the 9-8-12-8 exhibit excellent agreement with the experimental data. The amplitude of the unsteady envelopes for the two simulations are similar, except near the leading and trailing edges. Near the leading edge the results of the 3-3-4-3 simulation show more unsteadiness, while near the trailing edge the results of the 9-8-12-8 simulation show more unsteadiness.

\section{CONCLUSIONS}

A series of numerical simulations have been performed for flow through a two-stage low-pressure turbine. The simulations included two different operating conditions (takeoff and cruise), two blade count approximations and two different methods for processing the boundary layer information. Comparisons between the predicted results and the experimental data indicate:

- the effects of blade count approximation increase with wetted distance along the airfoil suction surface (i.e., in regions where unsteadiness is the largest)

- the method of obtaining/processing boundary layer information in the simulations must be consistent with the experimental techniques

- the effects of boundary layer clipping were generally more significant than the effects of blade count approximation
- the predicted unsteady displacement thickness histories showed fair agreement with the experimental data, but much better agreement than in a previous study

- the time-averaged displacement thickness and airfoil loading distributions show excellent agreement with the experimental data

\section{ACKNOWLEDGEMENT}

The work of the first author was supported by NASA Glemn Research Center under Grant NCC3645.

\section{References}

[1] Simon, F. F. and Ashpis, D. E., "Progress in Modeling of Laminar to Turbulent Transition on Turbine Vanes and Blades," International Conference on Turbulent Heat Transfer, 1996, also NASA TM 107180.

[2] Hodson, H. P., "The Development of Unsteady Boundary Layers on the Rotor of an Axial Flow Turbine," AGARD CP-351, 1983.

[3] Hodson, H. P., "Measurements of WakeGenerated Unsteadiness in the Rotor Passages of Axial Flow Turbines," ASME Paper 84-GT$189,1984$.

[4] Hodson, H. P., "Boundary Layer Transition and Separation Near the Leading Edge of a HighSpeed Turbine Blade," Journal of Engineering for Gas Turbines and Power, Vol. 107, 1985, pp. $127-134$.

[5] Hodson, H. P., Huntsman, I. and Steele, A. B., "An Investigation of Boundary Layer Development in a Multistage LP Turbine," Journal of Turbomachinery, Vol. 116, 1994, pp. 375-383.

[6] Halstead, D. E., Wisler, D. C., Okiishi, T. H., Walker, G. J., Hodson, H. P. and Shin, H.-W., "Boundary Layer Development in Axial Compressors and Turbines - Part 1 of 4: Composite Picture," ASME Paper 95-GT-461, Houston, $\mathrm{TX}, 1995$, also published in the ASME Journal of Turbomachinery.

[7] Halstead, D. E., Wisler, D. C., Okiishi, T. H.; Walker, G. J., Hodson, H. P. and Shin, H.-W., "Boundary Layer Development in Axial Compressors and Turbines - Part 3 of 4: LP Turbines," ASME Paper 95-GT-463, Houston, TX, 1995, also published in the ASME Journal of Turbomachinery. 
[8] Qiu, S. and Simon, T. W., "An Experimental Investigation of Transition as Applied to Low Pressure Turbine Suction Surface Flows," ASME Paper 97-GT-455, Orlando, Fl.

[9] Sohn, K. H., Slyne, R. J. and Dewitt, K. J., "Experimental Investigation of Boundary Layer Behavior in a Simulated Low Pressure Turbine," ASME Paper 98-GT-34, International Gas Turbine and Aeroengine Congress and Exhibition, Stockholm, Sweden, June 2-5, 1998.

[10] Boyle, R. J., Lucci, B. L., Verhoff, V. G., Camperchioli, W. P. and La, H., "Aerodynamics of a Transitioning Turbine Stator Over a Range of Reynolds Numbers," 98-GT-285, International Gas Turbine and Aeroengine Congress and Exhibition, Stockholm, Sweden, June 2-5, 1998.

[11] Mayle, R. E., "The Role of Laminar-Turbulent Transition in Gas Turbine Engines," ASME Paper 91-GT-261, Orlando, FL, 1991.

[12] Reshotko, E., "Boundary Layer Instability, Transition and Control," AIAA Paper 94-0001, Reno, NV, 1994.

[13] Gostelow, J. P., Blunder, A. R. and Walker, G. J., "Effects of Free-Stream Turbulence and Adverse Pressure Gradients on Boundary Layer Transition," ASME Journal of Turbomachinery, Vol. 116, 1994, pp. 392-404.

[14] Gostelow, J. P., Melwani, N. and Walker, G. J., "Effects of Streamwise Pressure Gradient on Turbulent Spot Development, ASME Paper 95GT-303, Houston, TX, 1995.

[15] Boyle, R. J. and Simon, F. F., "Mach Number Effects on Turbine Blade Transition Length Prediction," ASME Paper 98-GT-367, International Gas Turbine and Aeroengine Congress and Exhibition, Stockholm, Sweden, June 2-5, 1998, also accepted for publication in the ASME Journal of Turbomachinery.

[16] Chernobrovkin, A. and Lakshminarayana, B., "Development and Validation of Navier-Stokes Procedure for Turbomachinery Unsteady Flow," AIAA Paper 97-3281, Seattle, WA, 1997.

[17] Kang, D. J. and Lakshminarayana, B., "Numerical Prediction of Unsteady Transitional Flow Due to Rotor Stator Interaction," AIAA Paper 97-2752, Seattle, WA, 1997.
[18] Huang, P. G. and Xiong, G., "Transition and Turbulence Modeling of Low Pressure Turbine Flows," AIAA Paper 98-0339, Reno, NV, 1998.

[19] Eulitz, F. and Engel, K., "Numerical Investigation of Wake Interaction in a Low Pressure Turbine," ASME Paper 98-GT-563, International Gas Turbine and Aeroengine Congress and Exhibition, Stockholm, Sweden, June 2-5, 1998.

[20] Dorney, D. J., Ashpis, D. E., Halstead, D. E. and Wisler, D. C., "Study of Boundary Layer Devlopment in a Two-Stage Low-Pressure Turbine," AIAA 99-0742, 37th Aerospace Sciences Meeting, Reno, NV, January 11-14, 1999.

[21] Dorney, D. J., and Verdon, J. M., "Numerical Simulations of Unsteady Cascade Flow," ASME Journal of Turbomachinery, Vol. 116, No. 4, October, 1994, pp. 665-675.

[22] Baldwin, B. S., and Lomax, H., "Thin Layer Approximation and Algebraic Model for Separated Turbulent Flow", AIAA Paper 78-257, Huntsville, AL, January, 1978.

[23] Davis, R. L., Hobbs, D. E., and Weingold, H. D., "Prediction of Compressor Cascade Performance Using a Navier-Stokes Technique," ASME Journal of Turbomachinery, Vol. 110, No. 4, October, 1988, pp. 520-531.

[24] Abu-Ghannam, B. J., and Shaw, R., "Natural Transition of Boundary Layers - The Effects of Turbulence, Pressure Gradient, and Flow History," IMechE Journal of Mechanical Engineering Science, Vol. 22, No. 5, 1980, pp. 213-228.

[25] Dhawan, S., and Narasimha, R., "Some Properties of Boundary Layer Flow During Transition from Laminar to Turbulent Motion," Journal of Fluid Mechanics, Vol. 3., 1958.

[26] Dorney, D. J., "A Comparative Study of Four Algebraic Transition Models," SAE Journal of Aerospace, Vol. 103, Section 1, 1994, pp. 112119.

[27] Dorney, D. J., and Ashpis, D., "Study of Low Reynolds Number Effects on the Losses in LowPressure Turbine Blade Rows," AIAA 98-3575, 34th AIAA/ASME/SAE/ASEE Joint Propulsion Conference, Cleveland, OH, July 13-15, 1998, also to appear in the International Journal of Turbo and Jet Engines. 
[28] Roberts, W. B., "Calculation of Laminar Separation Bubbles and Their Effect on Airfoil Performance," AIAA Paper 79-0285, New Orleans, LA, January, 1979.

[29] Davis, R. L., Carter, J. E., and Reshotko, E., "Analysis of Transitional Separation Bubbles on Infinite Swept Wings," AIAA Journal, Vol. 25, No. 3, March, 1987, pp. 421-428.

[30] Halstead, D. E., Wisler, D. C., Okiishi, T. H., Walker, G. J., Hodson, H. P. and Shin, H.W. "Boundary Layer Development in Axial Compressors and Turbines - Part 4 of 4: Computations and Analyses," ASME Paper 95-GT-463, Houston, TX, 1995, also published in the ASME Journal of Turbomachinery. 


\section{Low Speed Research Turbine}

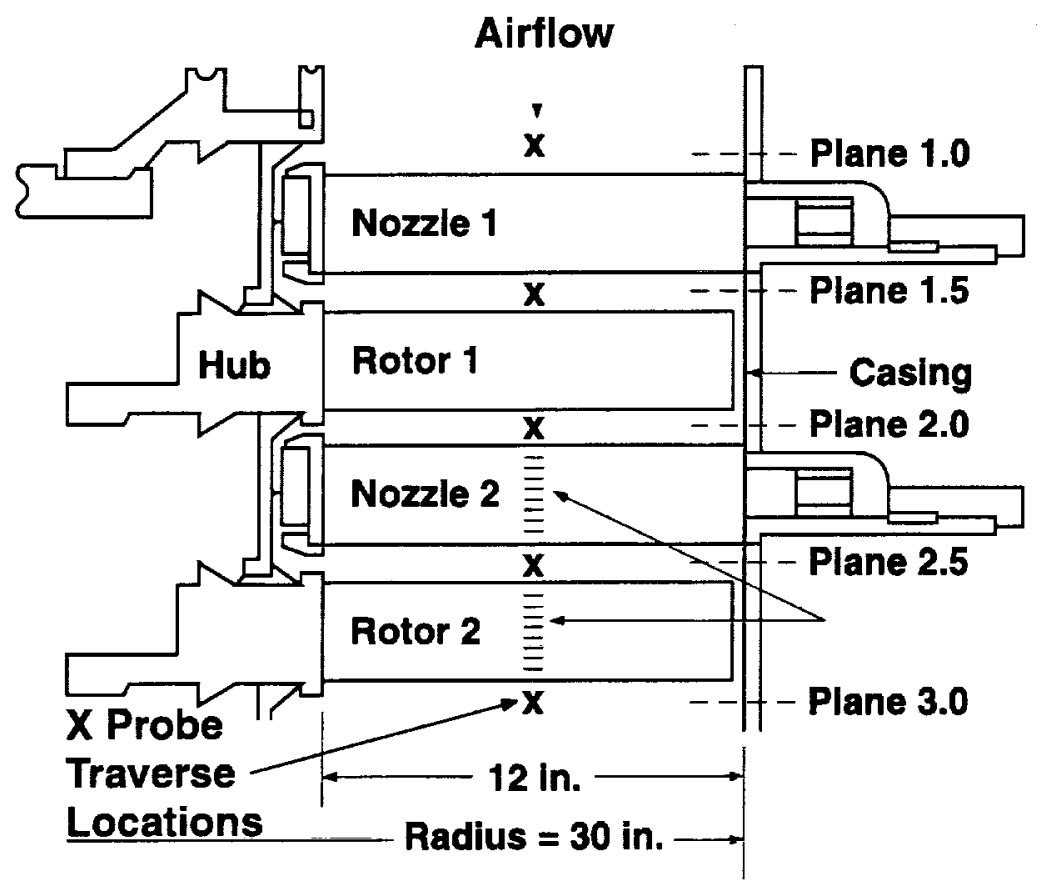

- Models low - pressure turbine blading of a commercial GEAE engine family.

- Instrumentation

- X hot - film probe in axial - tangential plane

- midspan only

- supports modified to mitigate prong vibration

- Nominal Design Point:

$R P M=600 \quad U_{\text {mid }}=126 \mathrm{ft} / \mathrm{s}$ $\phi=1.03 \quad \psi=1.17$

$k_{\text {rotor }}=1.3 \quad k_{\text {nozzle }}=0.75$

$\mathrm{Re}_{S S L}=100 k-500 k$

Figure 1: Experimental two-stage LPT turbine facility. 


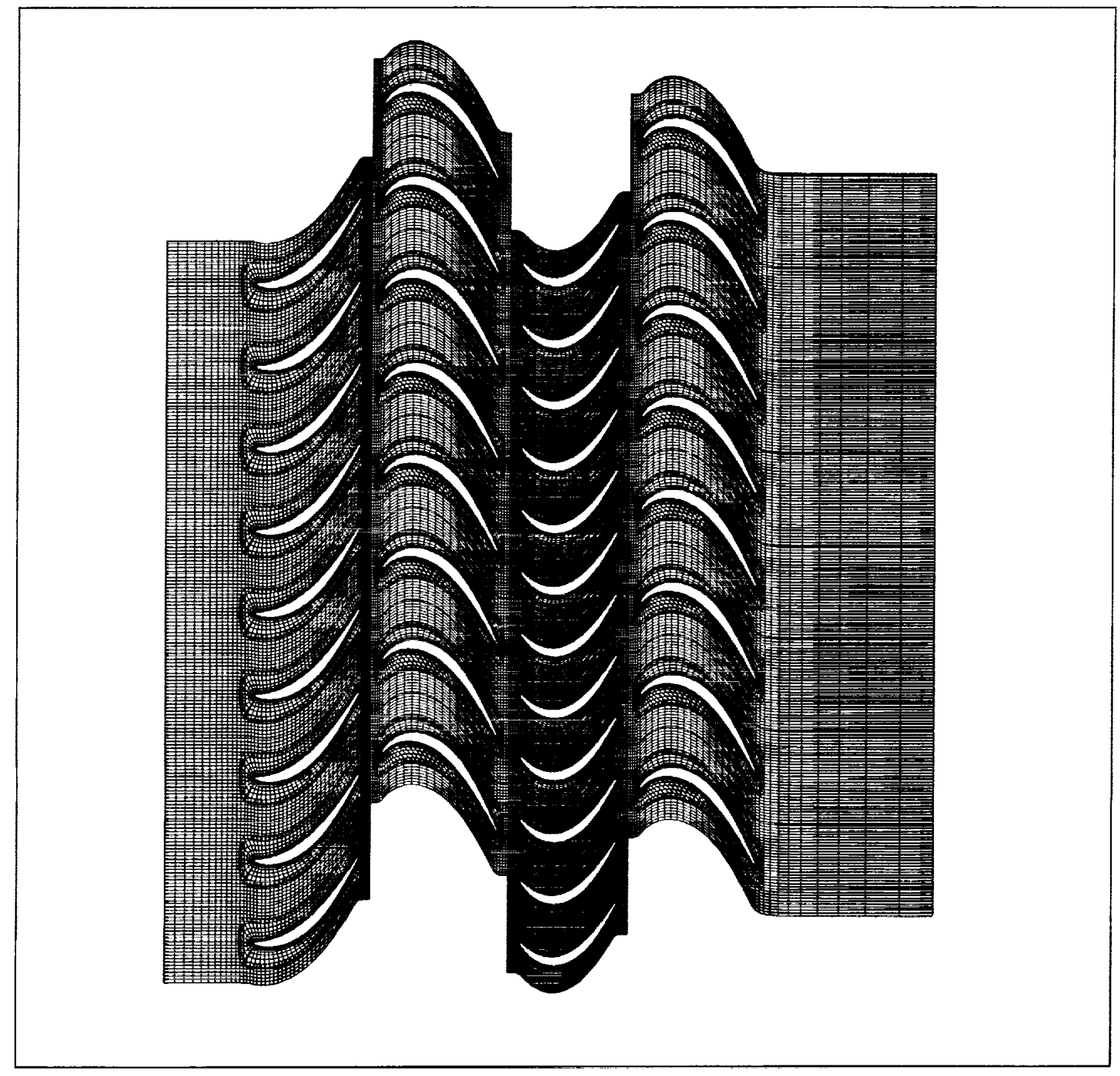

Figure 2: Computational grid for two-stage LPT turbine. 


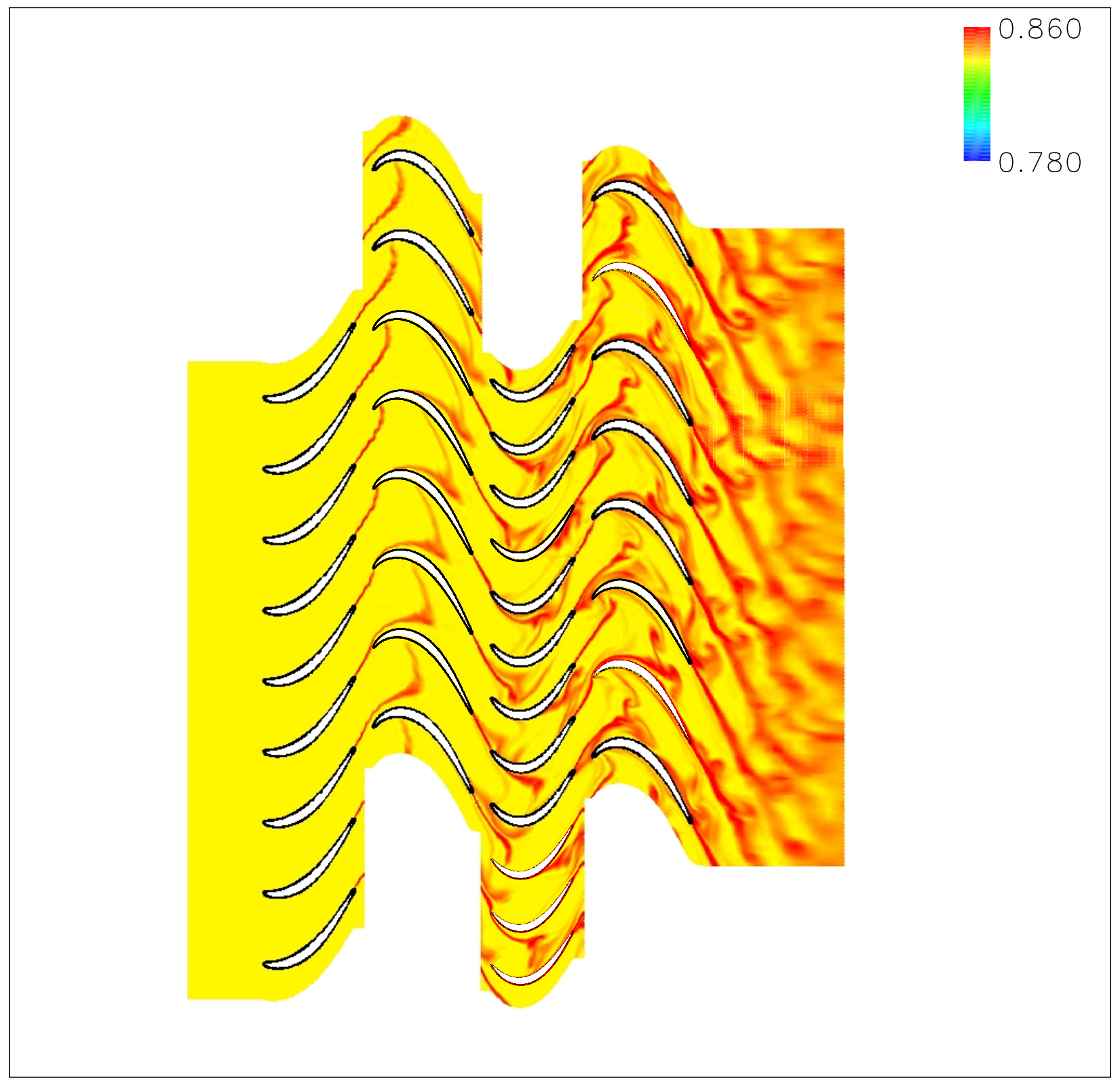

Figure 3: Instantaneous non-dimensional entropy contours - Point 5A. 


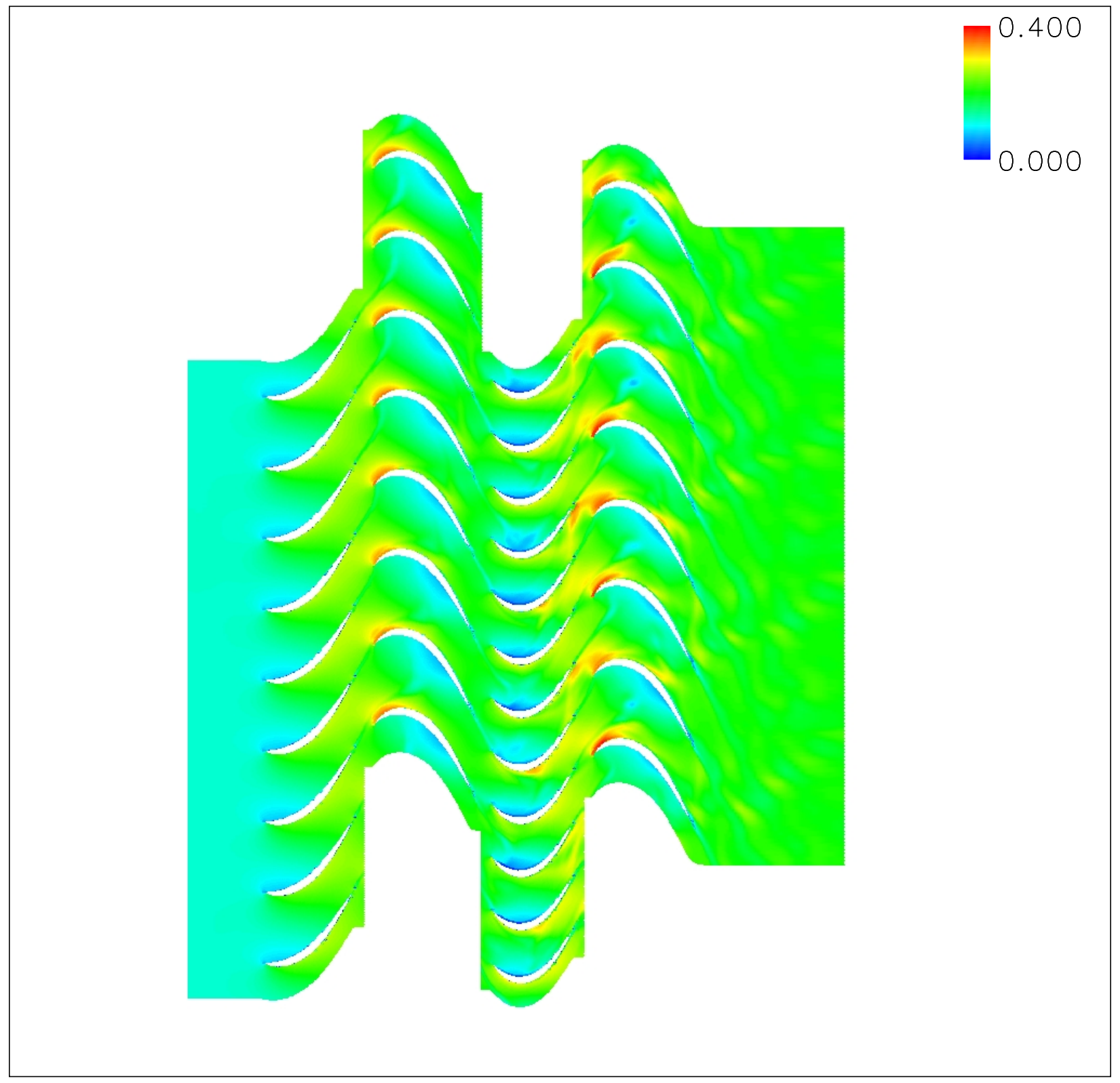

Figure 4: Instantaneous Mach contours - Point 5A. 


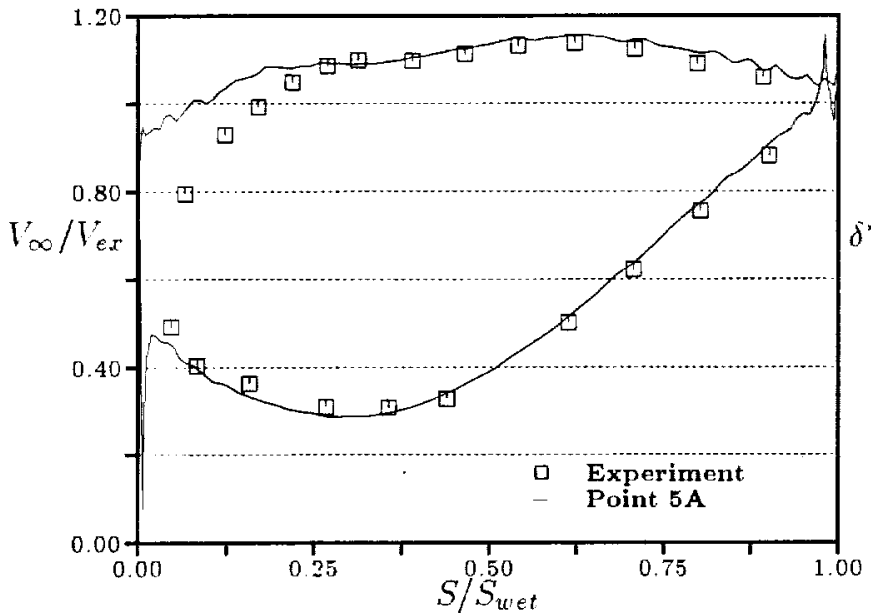

Figure 5: Normalized loading on nozzle-2, Point 5A.

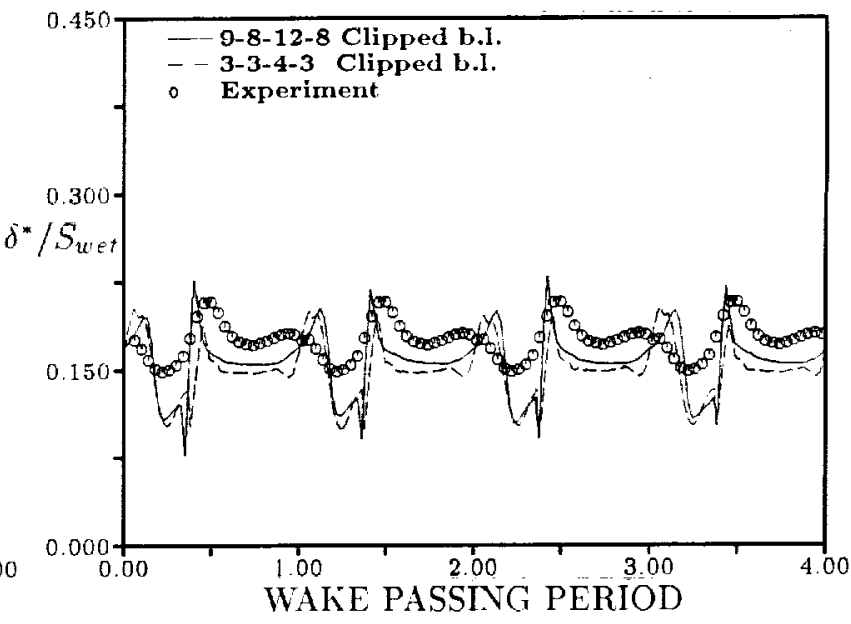

Figure 7: Displacement thickness history, 50\% s.s., Point 5A, nozzle-2.

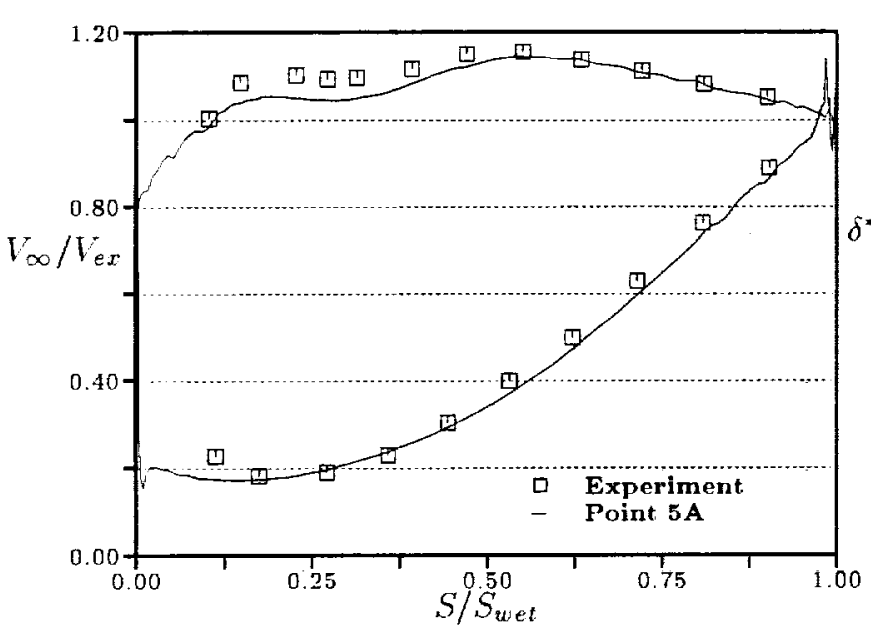

Figure 6: Normalized loading on rotor-2, Point $5 \mathrm{~A}$.

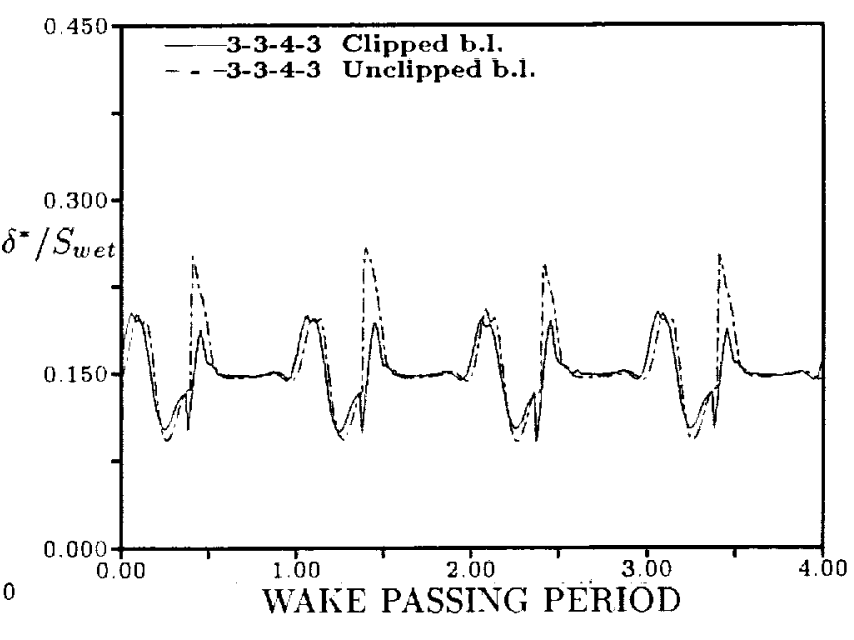

Figure 8: Displacement thickness history, 50\% s.s., Point 5A, nozzle-2. 

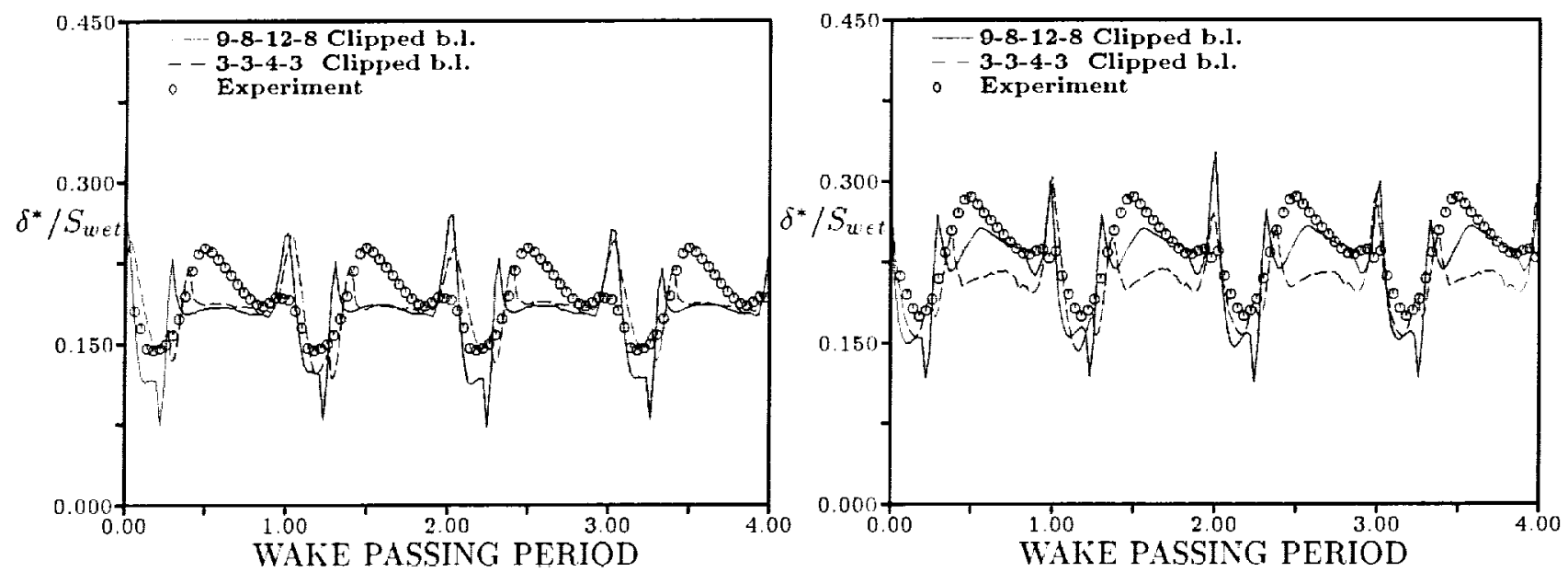

Figure 9: Displacement thickness history, $68 \%$ s.s., Figure 11: Displacement thickness history, $82 \%$ s.s., Point 5A, nozzle-2.

Point 5A, nozzle-2.
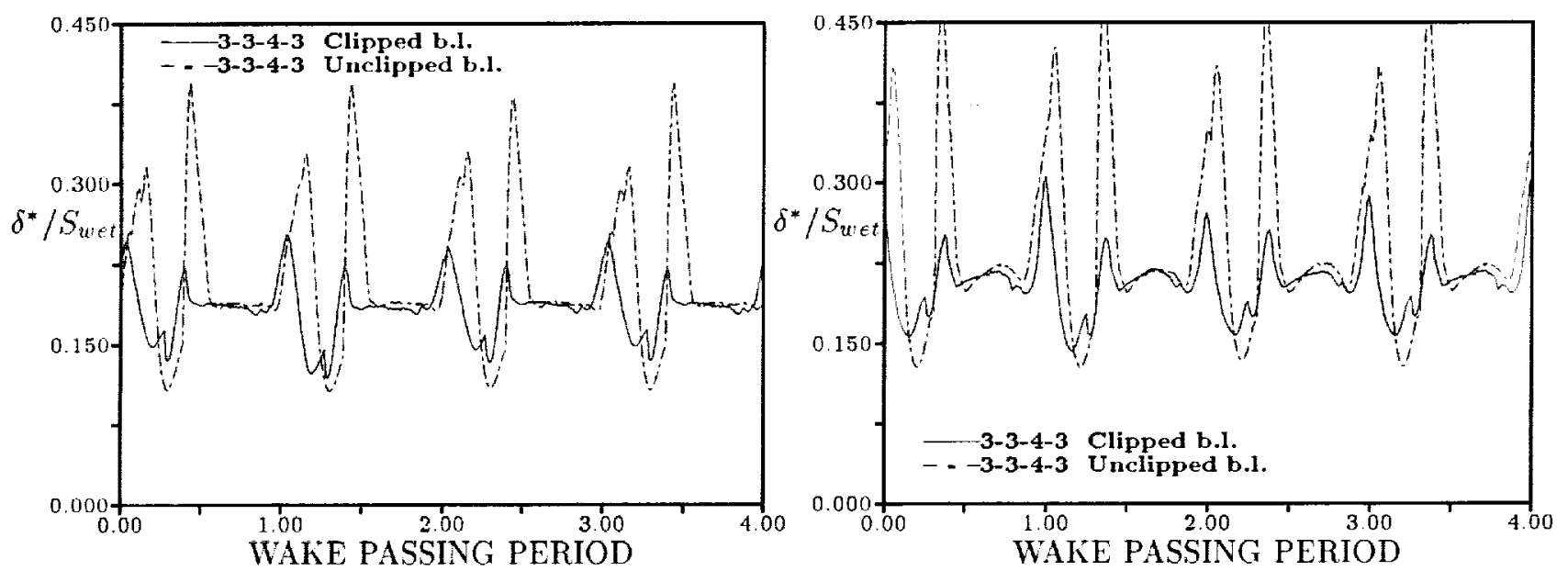

Figure 10: Displacement thickness history, $68 \%$ s.s., Point 5A, nozzle-2.

Figure 12: Displacement thickness history, $82 \%$ s.s., Point 5A, nozzle-2. 


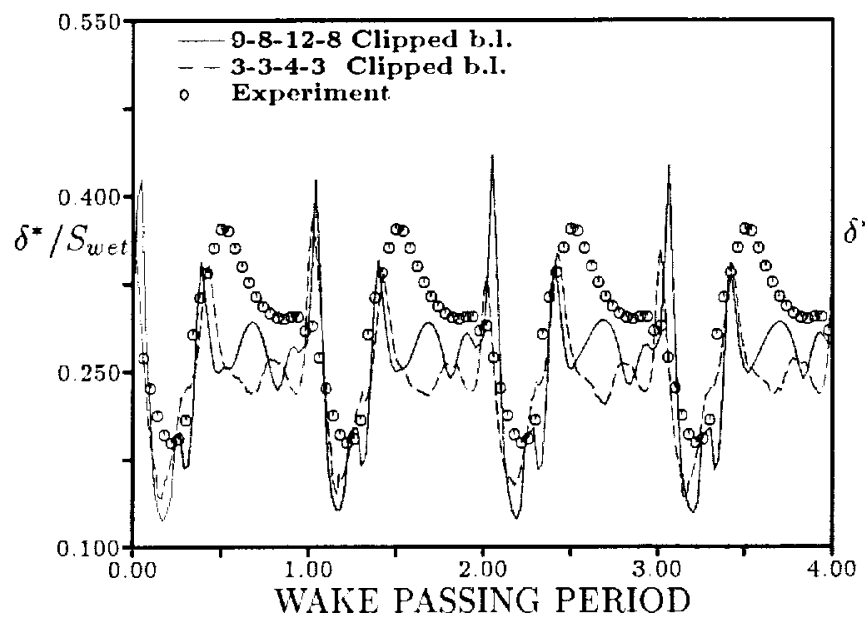

Figure 13: Displacement thickness history, $94 \%$ s.s., Point 5A, nozzle-2.

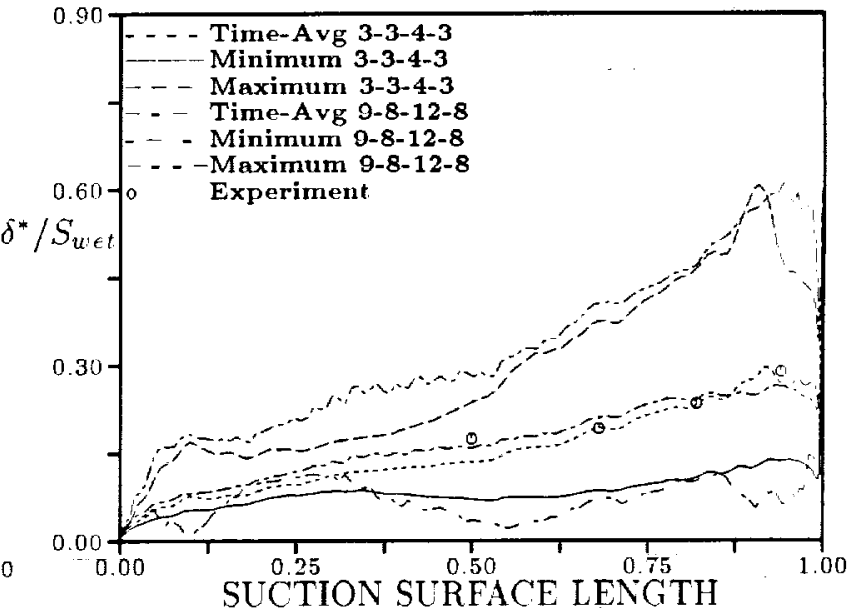

Figure 15: Displacement thickness envelope, Point 5 A nozzle-2

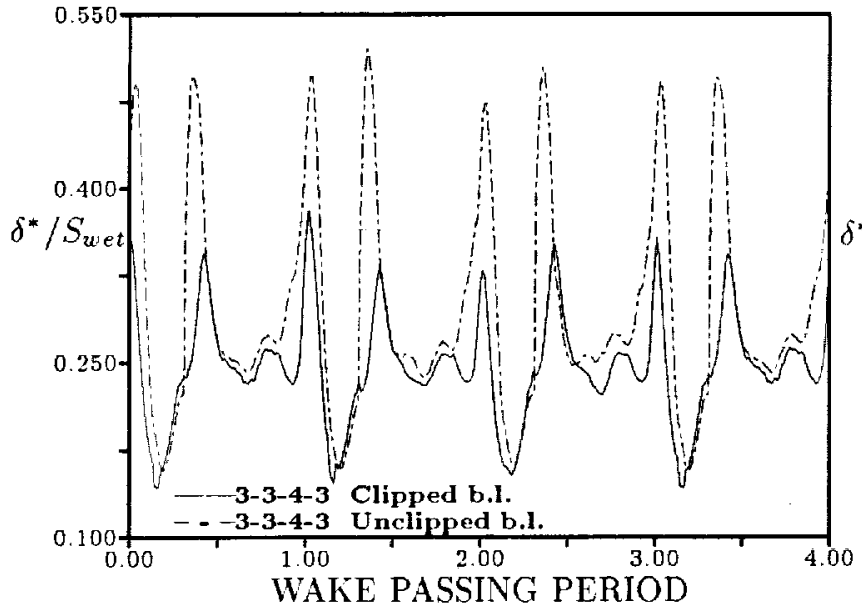

Figure 14: Displacement thickness history, 94\% s.s., Point 5A, nozzle-2.

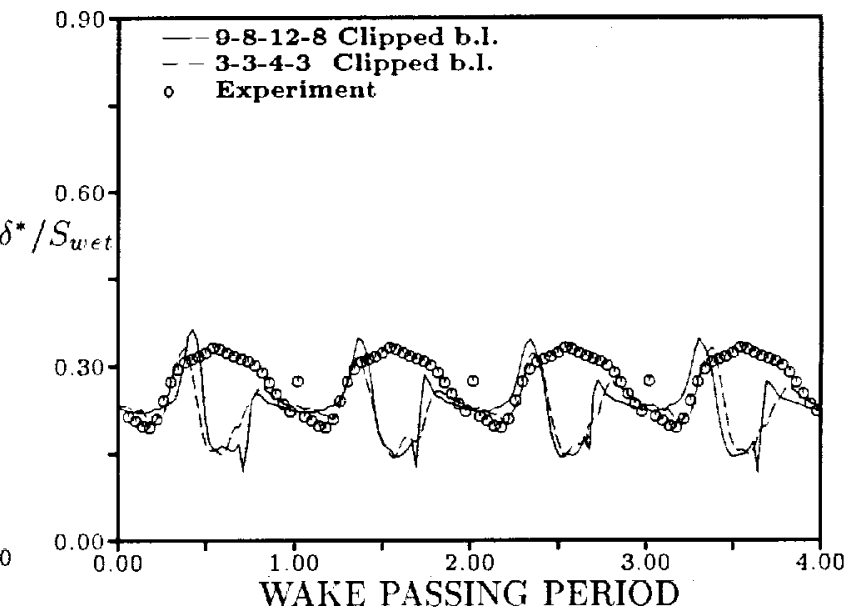

Figure 16: Displacement thickness history, 50\% s.s., Point 5D, nozzle-2. 


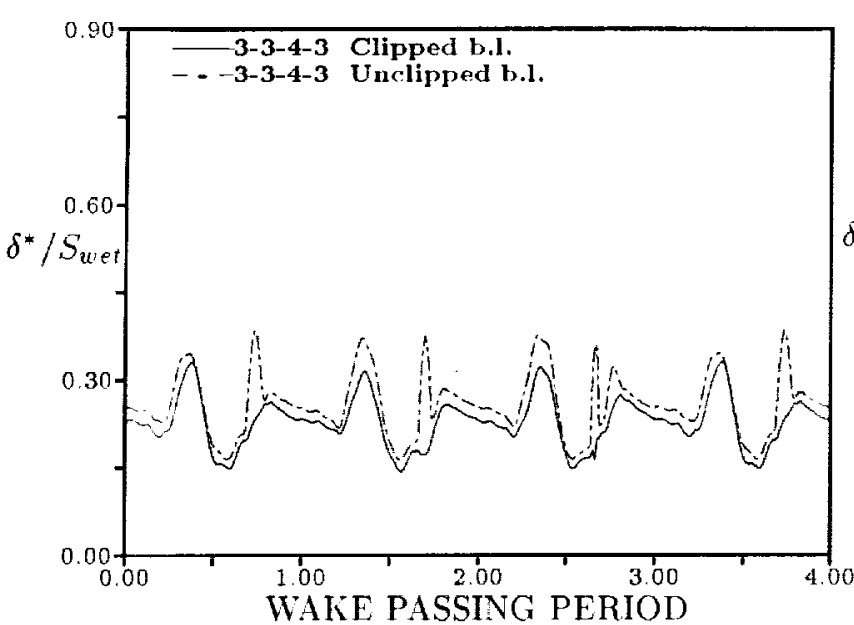

Figure 17: Displacement thickness history, $50 \%$ s.s., Point 5D, nozzle-2.

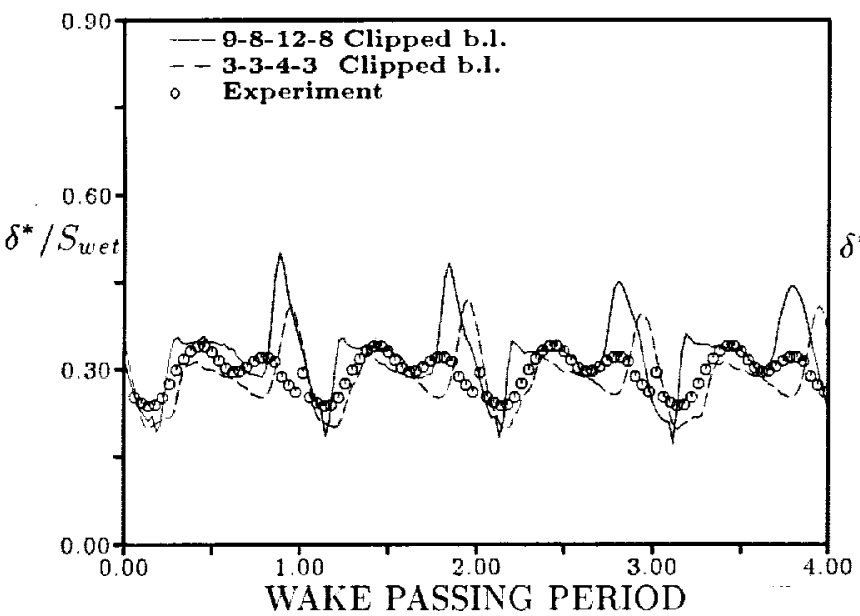

Figure 18: Displacement thickness history, $68 \%$ s.s., Point 5D, nozzle-2.

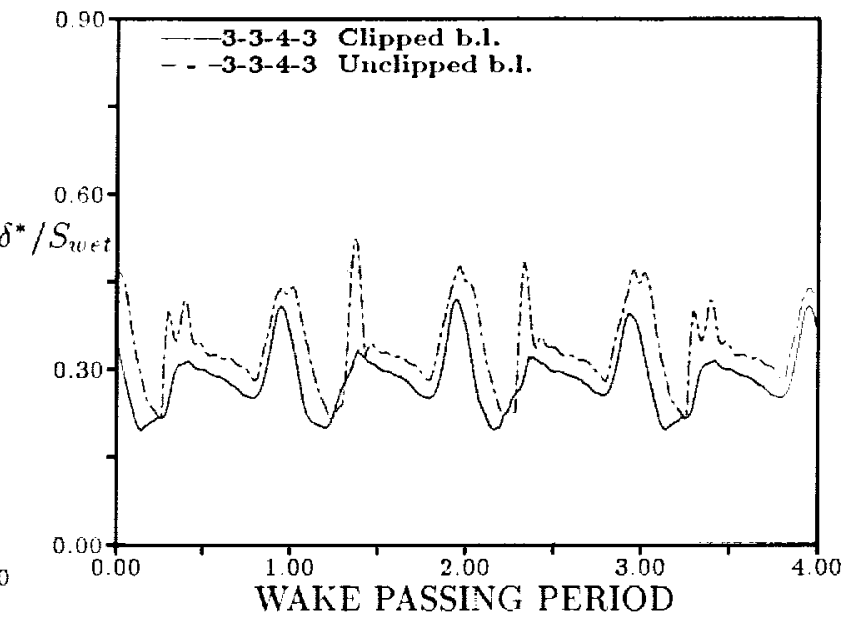

Figure 19: Displacement thickness history, $68 \%$ s.s., Point 5D, nozzle-2.

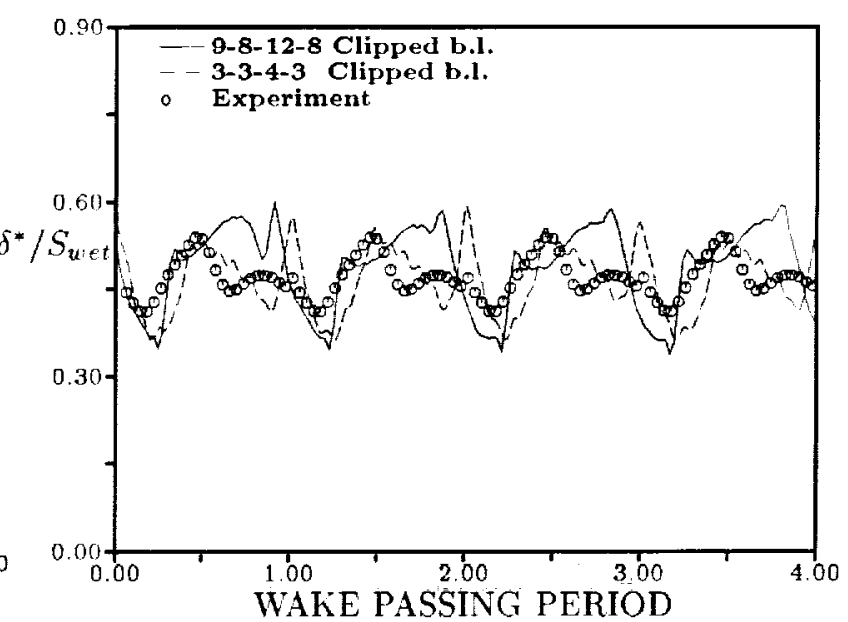

Figure 20: Displacement thickness history, $82 \%$ s.S., Point $5 \mathrm{D}$, nozzle-2. 


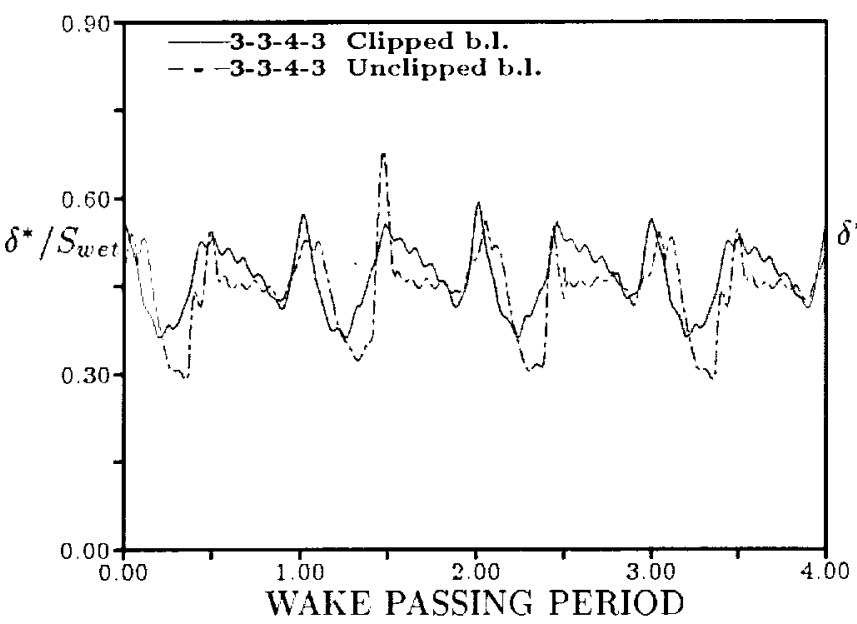

Figure 21: Displacement thickness history, $82 \%$ s.s., Point 5D, nozzle-2.

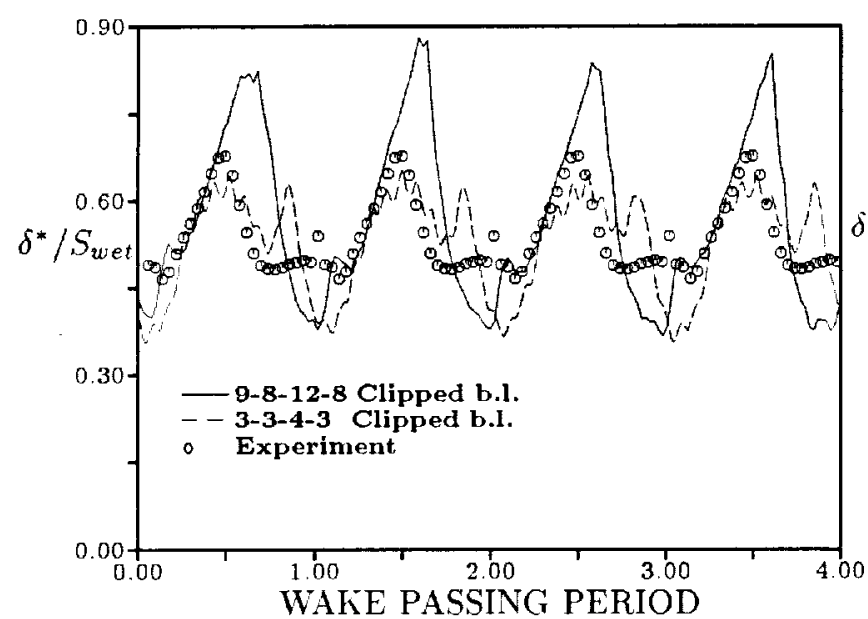

Figure 22: Displacement thickness history, $94 \%$ s.s., Point 5D, nozzle-2.

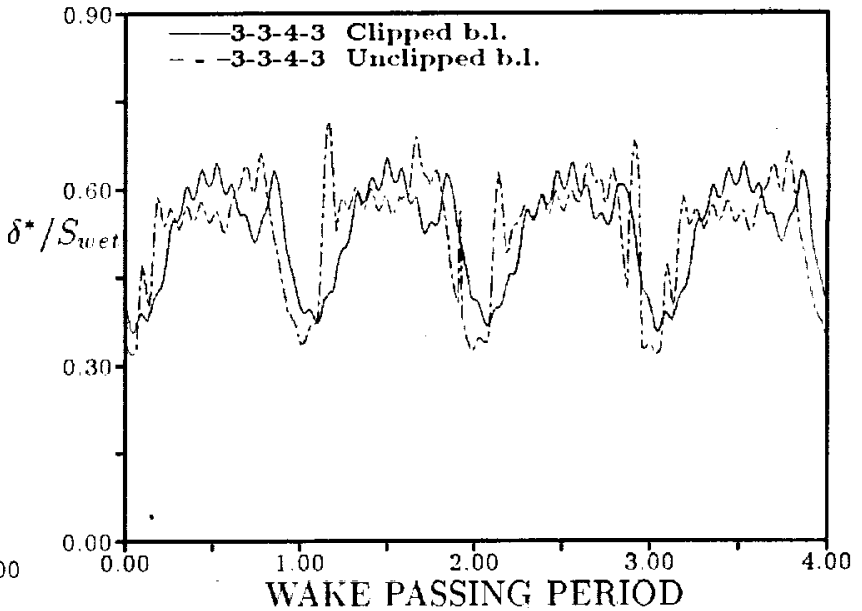

Figure 23: Displacement thickness history, 94\% s.s., Point 5D, nozzle-2.

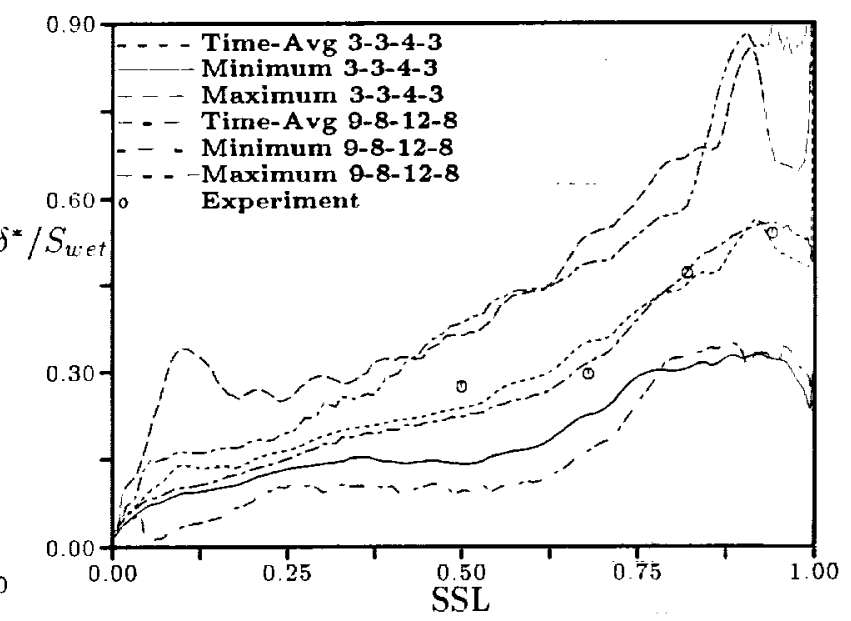

Figure 24: Displacement thickness envelope, Point 5 D nozzle-2 


\begin{tabular}{|c|c|c|c|}
\hline \multicolumn{3}{|c|}{ REPORT DOCUMENTATION PAGE } & $\begin{array}{l}\text { Form Approved } \\
\text { OMB No. 0704-0188 }\end{array}$ \\
\hline \multicolumn{4}{|c|}{ 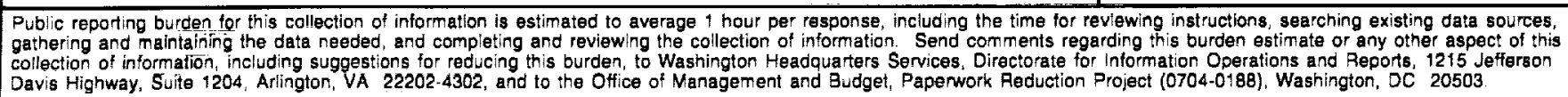 } \\
\hline 1. AGENCY USE ONLY (Leave blank) & $\begin{array}{l}\text { 2. REPOAT DATE } \\
\text { January } 2000\end{array}$ & & $\begin{array}{l}\text { VD DATES COVERED } \\
\text { echnical Memorandum }\end{array}$ \\
\hline \multicolumn{3}{|c|}{$\begin{array}{l}\text { 4. TITLE AND SUBTTLE } \\
\text { The Effect of Blade Count on Boundary Layer Development in a } \\
\text { Low Pressure Turbine }\end{array}$} & \multirow{2}{*}{$\begin{array}{l}\text { 5. FUNDING NUMBERS } \\
\text { WU-523-26-33-00 }\end{array}$} \\
\hline \multicolumn{3}{|c|}{$\begin{array}{l}\text { 6. AUTHOR(S) } \\
\text { Daniel J. Dorney, Horia C. Flitan, David E. Ashpis, and William J. Solomon }\end{array}$} & \\
\hline \multicolumn{3}{|c|}{$\begin{array}{l}\text { 7. PERFORMING ORGANIZATION NAME(S) AND ADDRESS(ES) } \\
\text { National Aeronautics and Space Administration } \\
\text { John H. Glenn Research Center at Lewis Field } \\
\text { Cleveland, Ohio } 44135-3191\end{array}$} & $\begin{array}{l}\text { 8. PERFORMING ORGANIZATION } \\
\text { REPORT NUMBER } \\
\text { E- } 12138\end{array}$ \\
\hline \multicolumn{3}{|c|}{$\begin{array}{l}\text { 9. SPONSORING/MONITORING AGENCY NAME(S) AND ADDRESS(ES) } \\
\text { National Aeronautics and Space Administration } \\
\text { Washington, DC 20546-0001 }\end{array}$} & $\begin{array}{l}\text { 10. SPONSORING/MONITORING } \\
\text { AGENCY REPORT NUMBER } \\
\\
\text { NASA TM-2000-209911 } \\
\text { AIAA-2000-0742 }\end{array}$ \\
\hline
\end{tabular}

11. SUPPLEMENTARY NOTES

Prepared for the 38th Aerospace Sciences Meeting and Exhibit sponsored by the American Institute of Aeronautics and Astronautics, Reno, Nevada, January 10-13, 2000. Daniel J. Dorney and Horia C. Flitan, Virginia Commonwealth University, Department of Mechanical Engineering, 601 West Main Street, P.O. Box 843015, Richmond, Virginia 23284-3015; David E. Ashpis, NASA Glenn Research Center; and William J. Solomon, Ohio Aerospace Institute, 22800 Cedar Point Road, Brook Park, Ohio 44142. Responsible person, David Ashpis, organization code 5820, (216) 433-8317.

\begin{tabular}{|l|l} 
12. . DISTRIBUTIONAAVAILABILITY STATEMENT & 12b. DISTRIBUTION CODE
\end{tabular}

Unclassified - Unlimited

Subject Categories: 02, 07, and $34 \quad$ Distribution: Nonstandard

This publication is available from the NASA Center for AeroSpace Information, (301) 621-0390.

13. ABSTRACT (Maximum 200 words)

Experimental data from jet-engine tests have indicated that turbine efficiencies at takeoff can be as much as two points higher than those at cruise conditions. Recent studies have shown that Reynolds number effects contribute to the lower efficiencies at cruise conditions. In the current study numerical simulations have been performed to study the boundary layer development in a two-stage low-pressure turbine, and to evaluate the models available for low Reynolds number flows in turbomachinery. In a previous study using the same geometry the predicted time-averaged boundary layer quantities showed excellent agreement with the experimental data, but the predicted unsteady results showed only fair agreement with the experimental data. It was surmised that the blade count approximation used in the numerical simulations generated more unsteadiness than was observed in the experiments. In this study a more accurate blade approximation has been used to model the turbine, and the method of post-processing the boundary layer information has been modified to more closely resemble the process used in the experiments. The predicted results show improved agreement with the unsteady experimental data.

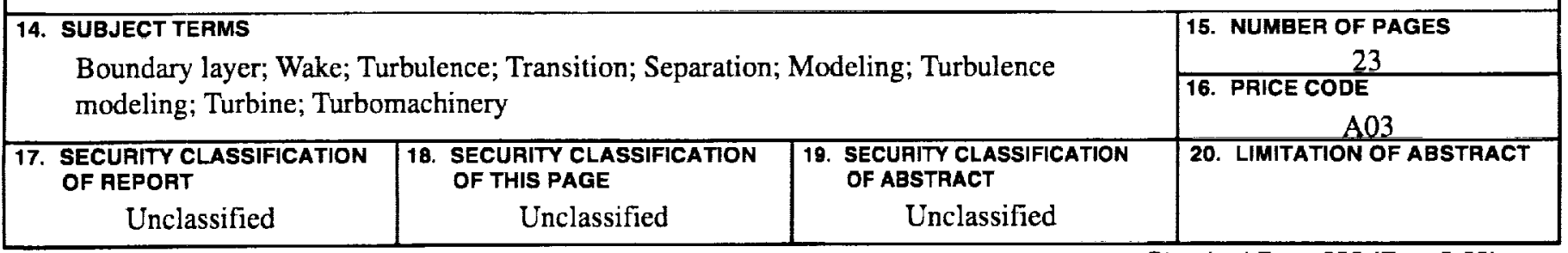

